\title{
Author Correction: Effects of Mesenchymal Stem Cell-Derived Exosomes on Experimental Autoimmune Uveitis
}

\author{
Lingling Bai ${ }^{1}$, Hui Shao ${ }^{2}$, Hongxing Wang ${ }^{3}$, Zhihui Zhang ${ }^{1}$, Chang Su ${ }^{1}$, Lijie Dong ${ }^{1}$, Bo Yu ${ }^{1}$, \\ Xiteng $\mathrm{Chen}^{1}$, Xiaorong $\mathrm{Li}^{1}$ \& Xiaomin Zhang ${ }^{1}$
}

Correction to: Scientific Reports https://doi.org/10.1038/s41598-017-04559-y, published online 28 June 2017

There are typographical errors in the legend of Figure 3 which should read:-

"Histological assessment of the retina in EAU. Sections of the retina were stained with hematoxylin and eosin, and evaluated for histological damage on 15 and 20 days post immunization. Representative H\&E staining images of PBS (A1 and C1, 15 days; A2 and C2 20 days), MSC-exo (A3, 15 days; A4, 20 days), and FIB-exo (C3, 15 days; C4, 20 days) treated groups are shown. Results are expressed quantitatively as histopathological scores (B and D). Values are expressed as the mean \pm SD of six rats ( 12 eyes) per group. * $\mathrm{P}<0.05$ ".

(i) Open Access This article is licensed under a Creative Commons Attribution 4.0 International License, which permits use, sharing, adaptation, distribution and reproduction in any medium or format, as long as you give appropriate credit to the original author(s) and the source, provide a link to the Creative Commons license, and indicate if changes were made. The images or other third party material in this article are included in the article's Creative Commons license, unless indicated otherwise in a credit line to the material. If material is not included in the article's Creative Commons license and your intended use is not permitted by statutory regulation or exceeds the permitted use, you will need to obtain permission directly from the copyright holder. To view a copy of this license, visit http://creativecommons.org/licenses/by/4.0/.

(C) The Author(s) 2018

${ }^{1}$ Tianjin Medical University Eye Hospital, Eye Institute \&School of Optometry and Ophthalmology, Tianjin, 300384,
P.R. China. ${ }^{2}$ Department of Ophthalmology and Visual Sciences, Kentucky Lions Eye Center, University of Louisville,
Louisville, KY, 40202, USA. ${ }^{3}$ Department of Ophthalmology, Chuiyangliu Hospital, Beijing, China. Correspondence and Louisville, KY, 40202, USA. ${ }^{3}$ Department of Ophthalmology, Chuiyangliu Hospital, Beijing, China. Correspondence and
requests for materials should be addressed toX.L. (email: lixiaorong@tmu.edu.cn) orX.Z. (email: xiaomzh@126.com) 